\title{
DEVELOPMENT AND VALIDATION OF LIQUID CHROMATOGRAPHIC METHOD FOR NAPROXEN AND ESOMEPRAZOLE IN BINARY COMBINATION
}

\author{
${ }^{a}$ SYED NAEEM RAZZAQ, ${ }^{b} M U H A M M A D$ ASHFAQ*, ${ }^{a}$ ISLAM ULLAH KHAN AND ${ }^{c} I R F A N A$ MARIAM
}

\author{
${ }^{a}$ Materials Chemistry Laboratory, Department of Chemistry, Faculty of Science and Technology, Government College University, Lahore-54000, Pakistan \\ ${ }^{b}$ Department of Chemistry, University of Gujrat, Gujrat-50700, Pakistan \\ 'Department of Chemistry, Queen Marry College, Lahore-54000 Pakistan
}

(Received: February 28, 2011 - Accepted: September 17, 2012)

\begin{abstract}
The present study reports the development and validation of a simple, economic and sensitive HPLC method for the concurrent determination of naproxen and esomeprazole in pharmaceutical formulations. Isocratic chromatography was performed with $\mathrm{C}-18$ column and mixture of phosphate buffer (pH 6.1 ) and acetonitrile in ratio of $(40: 60, \mathrm{v} / \mathrm{v})$ at $1.5 \mathrm{mlmin}^{-1}$. The eluents were monitored at $302 \mathrm{~nm}$ using UV detector. The method was isocratic in the range of 9.38 to 300 $\mu \mathrm{gml}^{-1}$ for naproxen and 0.5 to $16 \mu \mathrm{gml}^{-1}$ for esomeprazole. Validation of the method was performed by testing parameters like linearity, accuracy, precision, robustness, specificity, LOD and LOQ values. In the specificity the drugs were subjected to forced degradation studies like acidic, basic, oxidative and thermal stresses. Both the analytes were separated within three minutes. As the method separates the degradation products produced during forced degradation studies from the active analytes so it can be used not only for regular determination of naproxen and esomeprazole but also for their stability studies.
\end{abstract}

Key words: HPLC, acetonitrile, isocratic, specificity, forced degradation study.

\section{1-INTRODUCTION}

Naproxen (Fig.1) chemically designated as [(S)-6-methoxy-alpha-methyl2-naphthaleneacetic acid] is non-steroidal anti-inflammatory medicine that demonstrates both antipyretic and analgesic behavior [1-4]. It can be used for the remedy of various diseases, such as rheumatoid arthritis, juvenile rheumatoid arthritis, ankylosing spondylitis, osteoarthritis, primary dysmenorrheal and acute gout [5]. After taken orally, naproxen is partially metabolized to its 6-O-desmethylated active metabolite. Both the drug and its metabolite are then excreted through urine either as unchanged or in conjugation with sulphate or glucoronic acid [6-8].<smiles>COc1ccc2cc(C(C)C(=O)O)ccc2c1</smiles>

Fig.1. Chemical structure of naproxen.

Esomeprazole magnesium (Fig. 2) is a proton pump inhibitor chemically designated as bis(5-methoxy-2-[(S)-[(4-methoxy-3,5-dimethyl-2-pyridinyl) methyl]sulfinyl]-1H-benzimidazole-1-yl) magnesium trihydrate [9-10]. It is an optical isomer used for acid related diseases [11]. Esomeprazole is ultimately converted to its two metabolites, esomeprazole sulphone and 5-hydroxyesomeprazole [12].

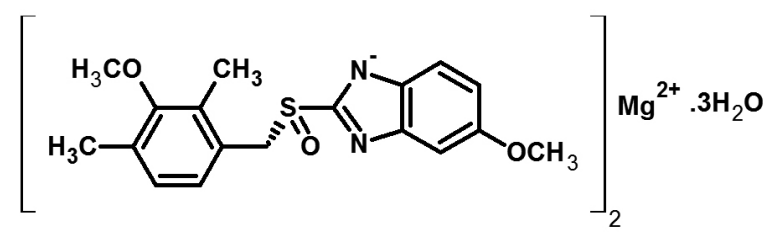

Fig.2. Chemical structure of esomeprazole magnesium.

Both naproxen and esomeprazole have been analysed by various techniques either alone or in combination with other drugs. The analytical methods existed for naproxen includes determination by capillary electrophoresis [13-15], spectrophotometry [16], micellar electrokinetic capillary chromatography [1718], HPLC [19-20] and spectrofluorometry [21-25]. Compared to naproxen only few analytical methods exist for the determination of esomeprazole [2629].
A careful literature survey did not reveal any single analytical technique for the determination of naproxen and esomeprazole simultaneously. Therefore, attempts were made to develop and validate an isocratic reverse phase HPLC method to determine both drugs simultaneously. We are currently engaged in binary combination analysis of different classes of drugs in synthetic mixtures and in pharmaceutical formulations [30-39]. The present work is therefore, aimed to attain the optimum chromatographic conditions for the determination of naproxen and esomeprazole simultaneously.

We describe in this paper a simple, cheap, sensitive and validated HPLC method with run time less than 3 minutes for the determination of naproxen and esomeprazole simultaneously in pharmaceutical formulations. The developed method can be applied to routine quality control analysis of drugs and for other analytical purposes.

\section{2-EXPERIMENTAL}

\subsection{Chemicals and Reagents}

Reference standards of both naproxen and esomeprazole with claimed percentage purity of 99.62 and $99.71 \%$ respectively were kindly gifted by Schazoo Zaka Laboratories (Lahore, Pakistan). Acetonitrile (chromatography grade), dipotassium hydrogen phosphate, potassium dihydrogen phosphate, sodium hydroxide, hydrochloric acid and hydrogen peroxide (analytical reagent grade) were procured from Fluka (Lahore, Pakistan). Double distilled water (prepared in our laboratory) was used for all the analysis. Filtration of the mobile phase was done using $0.45 \mu$ nylon filters procured from Millipore (USA).

2.2 Apparatus and chromatographic conditions

HPLC experiments were carried on a LC-20A system (Shimadzu, Japan) which was equipped with a 20AT pump, M20A UV-Visible detector, 20A degasser, CTO-20A column oven, and Rheodyne injection valve with a 20 $\mu \mathrm{L}$ loop. All the detections were performed at $302 \mathrm{~nm}$ and peak areas were calculated using Shimadzu Class VP HPLC software. Reversed-phase Hypersil ODS C1 8 column $(250 \times 4.6 \mathrm{~mm}, 5 \mu \mathrm{m}$ particle size $)$ at room temperature was used for carrying out all experiments. Mobile phase was prepared by mixing acetonitrile and phosphate buffer $(\mathrm{pH} 6.1)$ in ratio of $(60: 40, \mathrm{v} / \mathrm{v})$. Buffer preparation was made by taking $2.72 \mathrm{~g}$ of potassium dihydrogen phosphate and $0.525 \mathrm{~g}$ of dipotassium hydrogen phosphate in $1000 \mathrm{ml}$ of water and sonicated to dissolve. An external standard method was used isocratically and the flow rate of the mobile phase was $1.5 \mathrm{mlmin}^{-1}$.

\subsection{Preparation of standard solutions}

To prepare the standard solution, $187.5 \mathrm{mg}$ of naproxen and $10 \mathrm{mg}$ of esomeprazole were transferred to $25 \mathrm{ml}$ volumetric flask. $20 \mathrm{ml}$ of $0.1 \mathrm{~N}$ sodium hydroxide was added and sonicated for 10 minutes to dissolve both the drugs. After dissolution, the volume was made up to the mark with same solvent. $1 \mathrm{ml}$ of this solution was then diluted to $50 \mathrm{ml}$ with mobile phase. This 
furnished the concentrations of final solution equal to $150 \mu \mathrm{gml}^{-1}$ naproxen and $8 \mu \mathrm{gml}^{-1}$ esomeprazole.

\subsection{Preparation of sample solution}

The average weight of accurately weighed twenty tablets was determined and then these tablets were manually milled using pestle and mortar to a homogenized powder. An amount of the milled tablets equal to $187.5 \mathrm{mg}$ naproxen and $10 \mathrm{mg}$ of esomeprazole was transferred to a $25 \mathrm{ml}$ volumetric flask containing $20 \mathrm{ml}$ of $0.1 \mathrm{~N}$ sodium hydroxide and sonicated for ten minutes to extract all the drugs from the excipients. After this, the volume was made up to the mark with same solvent, cooled and then filtered. The filtrate was then diluted 50 times with mobile phase. The final concentration thus achieved was $150 \mu \mathrm{gml}^{-1}$ naproxen and $8 \mu \mathrm{gml}^{-1}$ esomeprazole.

\subsection{Linearity}

The calibration curves were prepared to evaluate linearity. For this purpose seven different concentrations in the range of 9.38 to $300 \mu \mathrm{gml}^{-1}$ for naproxen $\left(9.38,37.5,75,112.5,150,225\right.$ and $\left.300 \mu \mathrm{gml}^{-1}\right)$ and 0.5 to $16 \mu \mathrm{gml}^{-}$ ${ }^{1}$ for esomeprazole $\left(0.5,2,4,6,8,12\right.$ and $\left.16 \mu \mathrm{gml}^{-1}\right)$ were used. Triplicate measurements of each concentration were performed.

\subsection{Limit of detection and limit of quantitation}

To calculate the limit of detection (LOD) and limit of quantitation (LOQ), number of solutions with decreasing concentrations were prepared and then analysed. LOD and LOQ were then measured by evaluating the level at which the analyte can be readily detected (S/N 3:1) and quantified (S/N 10:1) with accuracy, respectively.

2.7 Accuracy

For carrying out accuracy, known quantities of the naproxen and esomeprazole standard solutions were added to the sample solutions that were previously quantified. Both the results were then compared. Three levels of solutions in the range of $50-150 \%$ of the nominal analytical concentration. i.e. $150 \mu \mathrm{gml}^{-1}$ naproxen and $8 \mu \mathrm{gml}^{-1}$ esomeprazole were prepared and analyzed for this purpose.

\subsection{Robustness}

Robustness is ability of a chromatographic method to give almost same results under somewhat different experimental conditions. To perform this parameter, small changes in the composition of the mobile phase, flow rate and $\mathrm{pH}$ of the buffer solution were made. Percentage recovery along with chromatographic parameters such as tailing factor, retention time and number of theoretical plates were calculated at those changed conditions.

\subsection{Forced degradation study}

For specificity demonstration, acidic, basic, oxidative and thermal stresses were applied as recommended by ICH.

For oxidative degradation study, $1 \mathrm{ml}$ of the stock standard solution was mixed with $0.5 \mathrm{ml}$ of hydrogen peroxide, kept for one hour at room temperature and then diluted up to $50 \mathrm{ml}$ with mobile phase. For thermal degradation, $1 \mathrm{ml}$ of the standard stock solution was refluxed for 1hour, cooled and then diluted up to $50 \mathrm{ml}$ with mobile phase. For acidic degradative study, equal volumes of standard stock solution and $1 \mathrm{M}$ hydrochloric acid were mixed, kept at room temperature, neutralized with $1 \mathrm{M} \mathrm{NaOH}$ after one hour and then diluted to 50 $\mathrm{ml}$ with mobile phase. For basic degradation, equal volumes of standard stock solution and $1 \mathrm{M} \mathrm{NaOH}$ were mixed at room temperature, neutralized with $1 \mathrm{M}$ $\mathrm{HCl}$ after one hour and then diluted to $50 \mathrm{ml}$ with mobile phase. The stressed samples were analyzed by the developed method and the percentage recovery under every condition was calculated.

\section{3-RESULTS AND DISCUSSION}

In this work we presented a simple, fast, sensitive and accurate HPLC method for simultaneous determination of naproxen and esomeprazole in pharmaceutical formulations. During this study, main purpose was to use simple mobile phase that elute components with shorter retention time, acceptable tailing and good resolution between the naproxen, esomeprazole and the degradation products. Different mobile phases were tried to achieve the desired goal. After a long way investigation, the optimum conditions were found to be phosphate buffer $(\mathrm{pH} 6.1)$ and acetonitrile in ratio of $(40: 60$, $\mathrm{v} / \mathrm{v})$. Upon applying these chromatographic conditions, well-resolved peaks were achieved at retention times of 1.75 and 2.29 minutes for naproxen and esomeprazole, respectively. The chromatograms representing naproxen and esomeprazole peaks are given in Fig. 3 and Fig. 4.

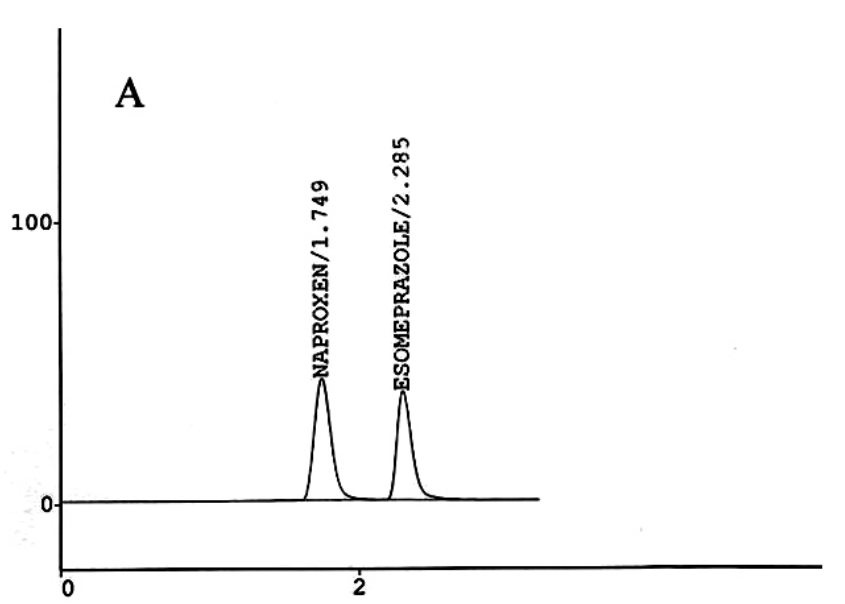

Fig. 3. Chromatogram of Naproxen and Esomeprazole reference standard

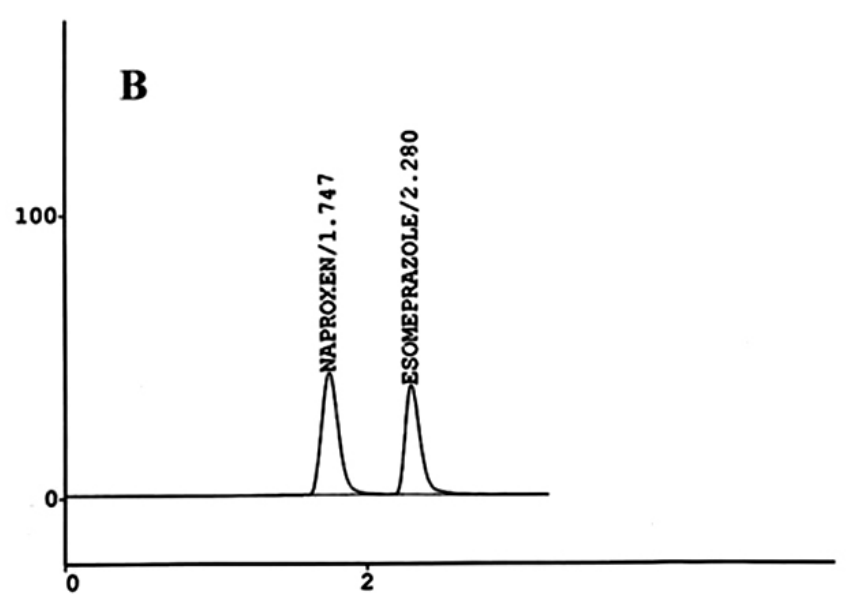

Fig. 4. Chromatogram of Naproxen and Esomeprazole in pharmaceutical formulations.

ICH guidelines were implemented for the validation of the method [40]. Validation of the method was performed by testing parameters like linearity, accuracy, precision, robustness, specificity, LOD and LOQ values.

The calibration curves were prepared to evaluate linearity. For this purpose seven different concentrations in the range of 9.38 to $300 \mu^{-1} \mathrm{gml}^{-1}$ for naproxen $\left(9.38,37.5,75,112.5,150,225 \mathrm{and}^{3} 30{\mu \mathrm{gml}^{-1}}^{-1}\right)$ and 0.5 to $16 \mu \mathrm{gml}^{-}$

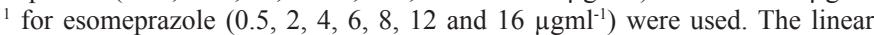
regression equation for naproxen was $Y=22495.12 \mathrm{X}+677.65$ with value of "r" equal to 0.998 whereas for esomeprazole, it was $\mathrm{Y}=5321.52 \mathrm{X}+260.97$ with value of "r" equal to 0.999 .

To calculate the limit of detection (LOD) and limit of quantitation (LOQ), a number of solutions with decreasing concentrations were prepared and then analysed. The LOD was found to be $0.12 \mu \mathrm{gml}^{-1}$ and $0.09 \mu \mathrm{gml}^{-1}$ for naproxen and esomeprazole respectively with $\mathrm{S} / \mathrm{N}$ ratio of $3: 1$. LOQ was found to be $0.40 \mu \mathrm{g} / \mathrm{ml}$ and $0.31 \mu \mathrm{g} / \mathrm{ml}$ for naproxen and esomeprazole, respectively with $\mathrm{S} / \mathrm{N}$ ratio of $10: 1$

For carrying out accuracy, known quantities of the naproxen and esomeprazole standard solutions were added to the sample solutions that were previously quantified. Both the results were then compared. Three levels of solutions in the range of $50-150 \%$ of the nominal analytical concentrations were prepared and analyzed for this purpose. Percentage recoveries given in Table 1 suggest the method to be highly accurate. 
Table.1. Accuracy of the proposed HPLC method.

\begin{tabular}{|c|c|c|c|c|c|c|}
\hline Drug & $\mathrm{n}$ & $\begin{array}{l}\text { level } \\
(\%)\end{array}$ & $\begin{array}{c}\text { Concentration } \\
\left(\mu \mathrm{gml}^{-1}\right)\end{array}$ & $\begin{array}{c}\text { Amount recovered } \\
\left(\mu \mathrm{gml}^{-1}\right)\end{array}$ & $\%$ recovery & $\%$ RSD \\
\hline \multirow[t]{3}{*}{ Esomeprazole } & 5 & 50 & 4.0 & 3.92 & 98.00 & 1.32 \\
\hline & 5 & 100 & 8.0 & 7.88 & 98.50 & 0.99 \\
\hline & 5 & 150 & 12.0 & 12.05 & 100.42 & 0.71 \\
\hline \multirow[t]{3}{*}{ Naproxen } & 5 & 50 & 75.0 & 74.36 & 99.15 & 1.16 \\
\hline & 5 & 100 & 150.0 & 148.15 & 98.77 & 1.02 \\
\hline & 5 & 150 & 225.0 & 222.16 & 98.74 & 0.69 \\
\hline
\end{tabular}

Intra and Inter day precision was performed to validate the precision of the proposed method. It was calculated in terms of Relative standard deviation (RSD \%) of the results obtained within the day and between the days. The results of intra-day and inter-day precision are presented in Table 2.

Table.2. Intra-day and Inter day precision of the proposed HPLC method.

\begin{tabular}{|c|c|c|c|c|c|c|}
\hline \multirow[t]{2}{*}{ Compound } & \multirow{2}{*}{\multicolumn{2}{|c|}{$\begin{array}{l}\text { Conc. } \\
\left(\mu g \mathrm{ml}^{-1}\right)\end{array}$}} & \multicolumn{2}{|c|}{ Intra-day Precision } & \multicolumn{2}{|c|}{ Inter-day precision } \\
\hline & & & Mean & $\operatorname{RSD}(\%)$ & Mean & $\operatorname{RSD}(\%)$ \\
\hline \multirow[t]{3}{*}{ Esomeprazole } & 4.0 & 5 & 4.03 & 1.22 & 4.07 & 1.82 \\
\hline & 8.0 & 5 & 8.08 & 1.05 & 7.98 & 1.49 \\
\hline & 12.0 & 5 & 11.84 & 1.15 & 11.81 & 1.56 \\
\hline \multirow[t]{3}{*}{ Naproxen } & 75.0 & 5 & 74.87 & 0.85 & 74.66 & 1.38 \\
\hline & 150.0 & 5 & 147.85 & 1.01 & 147.48 & 1.55 \\
\hline & 225.0 & 5 & 223.21 & 0.75 & 222.87 & 1.22 \\
\hline
\end{tabular}

For performing robustness, small changes in the composition of the mobile phase, flow rate and $\mathrm{pH}$ of the buffer solution were made. Percentage recovery along with chromatographic parameters such as tailing factor, retention time and number of theoretical plates were calculated at those modified conditions. The results are given in Table $3 \mathrm{a}$ and $3 \mathrm{~b}$. The results showed that slight variations in chromatographic conditions had negligible effects on the chromatographic parameters. It was thus concluded that the method is robust for the intended use.

Table 3a: Robustness study of Esomeprazole.

\begin{tabular}{|lllll|}
\hline Conditions & Assay \% & RT (min) & Theoretical plate & Tailing \\
\hline Acetonitrile: buffer (60:40) & 98.08 & 2.29 & 4782 & 1.11 \\
Acetonitrile:buffer (57:43) & 98.75 & 2.41 & 4818 & 1.06 \\
Acetonitrile:buffer (63:37) & 99.25 & 2.18 & 4675 & 1.18 \\
Flow rate (1.4ml/min) & 99.75 & 2.45 & 4798 & 1.05 \\
Flow rate (1.6 ml/min) & 100.29 & 2.15 & 4675 & 1.17 \\
Buffer (pH 6.3) & 98.79 & 2.26 & 4708 & 1.08 \\
Buffer (pH 5.9) & 98.05 & 2.25 & 4728 & 1.09 \\
\hline
\end{tabular}

Table 3b: Robustness study of Naproxen.

\begin{tabular}{|lcccc|}
\hline Conditions & Assay \% & RT (min) & Theoretical plate & Tailing \\
\hline Acetonitrile: buffer (60:40) & 98.08 & 1.75 & 3783 & 1.05 \\
Acetonitrile:buffer (57:43) & 98.75 & 1.83 & 3854 & 1.02 \\
Acetonitrile:buffer (63:37) & 99.25 & 1.69 & 3702 & 1.12 \\
Flow rate (1.4ml/min) & 99.75 & 1.88 & 3817 & 1.00 \\
Flow rate (1.6 ml/min) & 100.29 & 1.65 & 3714 & 1.10 \\
Buffer (pH 6.3) & 98.79 & 1.73 & 3687 & 1.07 \\
Buffer (pH 5.9) & 98.05 & 1.74 & 3708 & 1.07 \\
\hline
\end{tabular}

For specificity demonstration, acidic, basic, oxidative and thermal stresses were applied as recommended by ICH. Under oxidative stress, esomeprazole was degraded up to $65 \%$ whereas no degradation occurred for naproxen and the drug remains almost intact during this treatment. In case of thermal stress esomeprazole was degraded up to $6 \%$ and no degradation for naproxen. In acidic environment esomeprazole was degraded up to $90 \%$ and again no degradation for naproxen. Under basic conditions both the drugs remain intact and no degradation occurred for both the drugs. From the stress studies it is evident that naproxen is more stable under applied stress conditions whereas esomeprazole is more vulnerable to degradation and degraded easily especially under acidic and oxidative stress. The chromatograms under different stress conditions are represented in Figures 5-8.

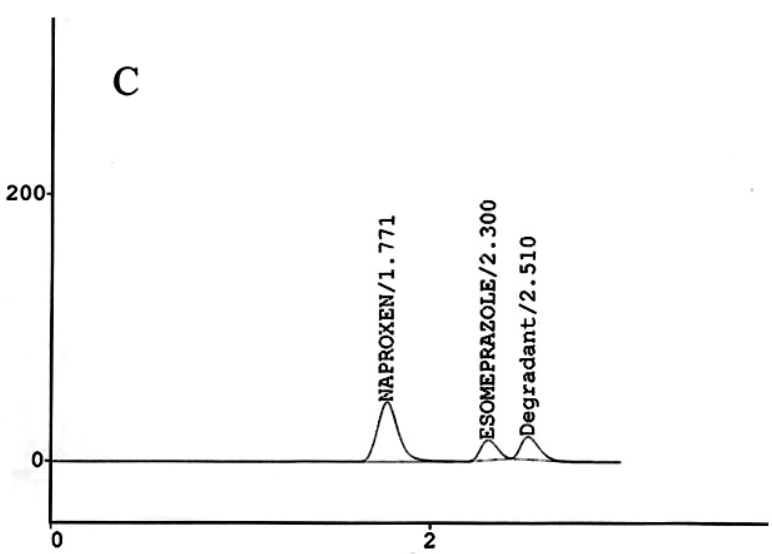

Fig. 5. Chromatogram of Naproxen and Esomeprazole under oxidative stress

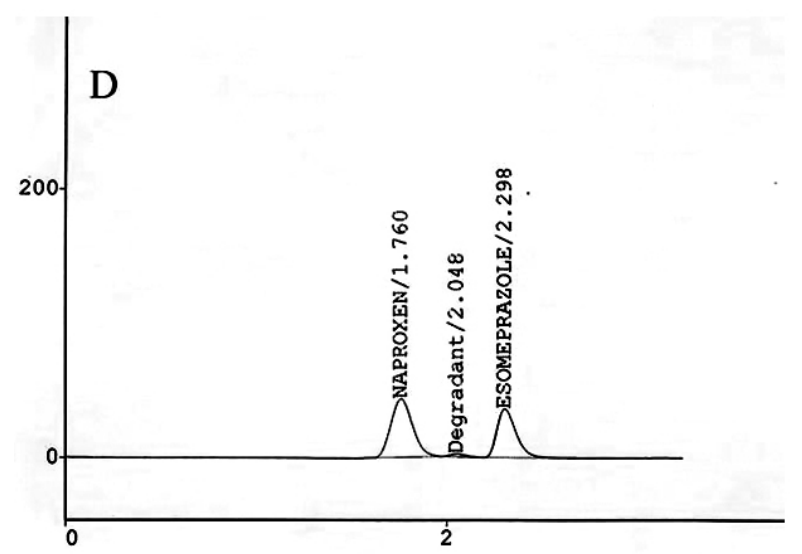

Fig. 6. Chromatogram of Naproxen and Esomeprazole under thermal stress 


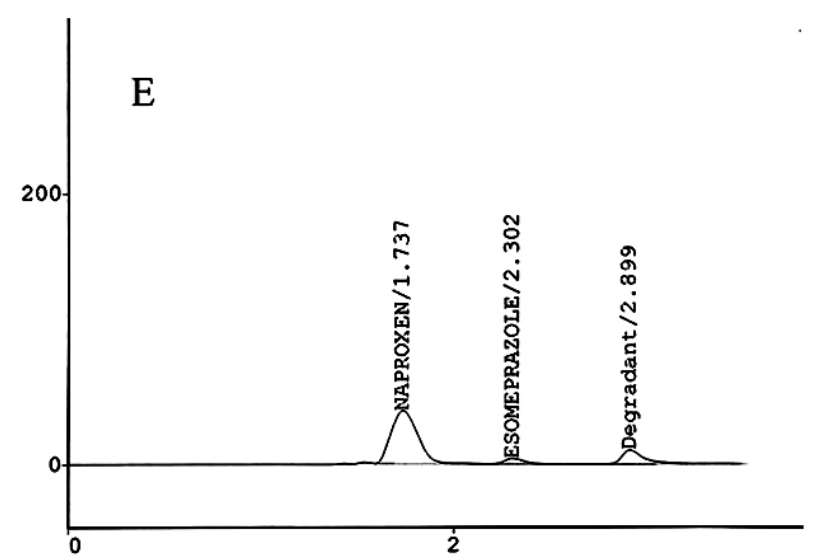

Fig. 7. Chromatogram of Naproxen and Esomeprazole under acidic stress

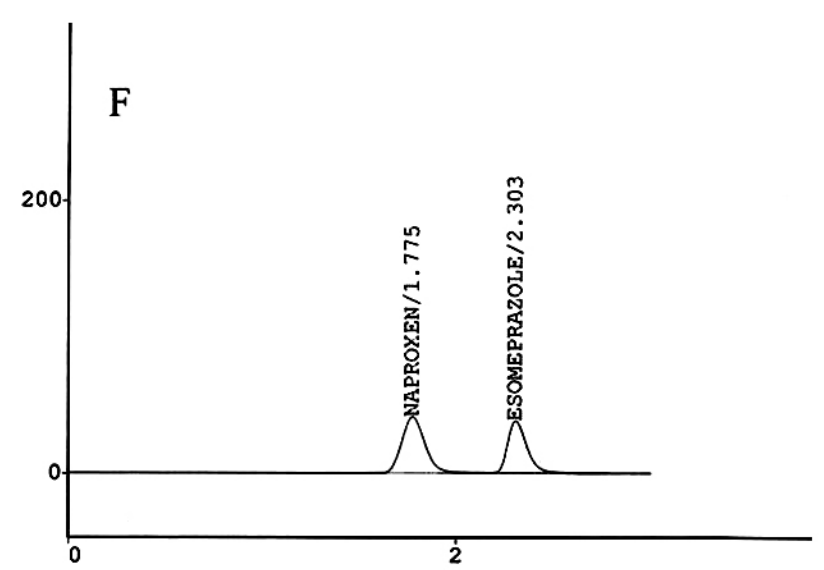

Fig. 8. Chromatogram of Naproxen and Esomeprazole under basic stress

\section{4-CONCLUSION}

A simple, fast, sensitive, isocratic and accurate reverse phase HPLC method has been described for simultaneous determination of naproxen and esomeprazole in pharmaceutical formulations. The proposed method was validated by testing its linearity, accuracy, precision, limits of detection and quantitation and specificity. The method was straightforward and simpler than the commonly used HPLC methods involving ion pair or derivatization. The method was good enough to separate the peaks of active pharmaceutical ingredients (APIs) from the degradation products. Shorter run time i.e., less than three minutes allows its suitability not only for routine determination of naproxen and esomeprazole but also for stability studies.

\section{5-REFERENCES}

1. H. Sevelius, R. Runkel, E. Segre, S.S. Bloomfield. Br J Clin Pharmac., 10, 259(1980)

2. M.L. Capone, S. Tacconelli, M.G. Sciulli, P. Anzellotti, L.D. Francesco, G. Merciaro, P.D. Gregorio, P. Patrignani. J Pharmacol Exp Ther., 322, 453(2007)

3. S. Moyer. Cephalalgia., 6, 77(1986)

4. E.J. Segre. Reprod Med., 25, 222(1980)

5. H. Paulus, D. Furst, S.H. Dromgoole. Drugs for Rheumatic Disease, Churchill Livingstone, New York (1987)

6. G.F. Thompson, J.M. Collins. J. Pharm. Sci., 62, 937(1973)

7. Y. Sugawara, M. Fujihara, Y. Miura, K. Hayashida, T. Takahashi. Chem Pharm Bull., 26, 3312 (1978)

8. C.H. Kiang, C. Lee, S. Kushinsky. Drug Metab. Dispos., 17, 43(1989)

9. J.E.F. Reynolds. Martindale the extra pharmacopoeia, 34th ed.; Pharmaceutical Press: London, 1265(2005)

10. S.V.N. Raju, K. Purandhar, P.P. Reddy, G.M. Reddy, L.A. Reddy, K.S.
Reddy, K. Sreenath, K. Mukkanti, G.S. Reddy. Org. Process Res. Dev., 10, 33(2006).

11. T. Lind, L. Rydberg, A. Kylback, T. Andersson, G. Hasselgren, J. Holmberg, K. Rohss. Aliment. Pharmacol. Ther., 14, 861(2000)

12. T. Andersson, M. Hassan-Alin, G. Hasselgren, K. Rohss, L.Weidolf. Clin. Pharmacokinet., 40, 411(2001)

13. J.R. Veraart, M.C.E. Groot, C. Gooijer, H. Lingeman, N.H. Velthorst, U.A.T. Brinkman. Analyst. 124, 115(1999)

14. J. Caslavska, E. Gassmann, W. Thormann. J. Chromatogr. A., 709, 147(1995)

15. J.R. Veraart, C. Gooijer, H. Lingeman, N.H. Velthorst, U.A.T. Brinkman, J. Chromatogr. B Biomed. Appl. 719, 199(1998)

16. I. Panderi, M. P. Poulou. Analyst. 119, 697(1994)

17. C. Albrecht, J. Reichen, J. Visser, D.K.F. Meijer, W. Thormann. Clin. Chem., 43, 2083(1997)

18. A. Schmutz, W. Thormann. Electrophoresis, 15, 1295(1994)

19. T. Karidas, A. Avgerinos, S. Malamataris. Anal. Lett., 26, 2341(1993)

20. H. Suh, H.W. Jun, G.W. Lu. J. Liquid Chromatogr., 18, 3105(1995)

21. A. Navalón, R. Blanc, M. del Olmo, J.L. Vilchez. Talanta, 48, 469(1999)

22. J.A.M. Pulgarın, L.F.G. Bermejo. Anal. Chim. Acta., 373, 119(1998)

23. T. P. Ruiz, C. M. Lozano, V. Tomas, J. C. Fresenius J. Anal. Chem., 361, 492(1998)

24. D.G. Konstantianos, P.C. Ioannou. Analyst, 121, 909(1996)

25. D.G. Konstantianos, P.C. Ioannou, E. Stratikos. Anal. Chim.Acta., 290, 34(1994)

26. N. Yasui-Furukori, Y. Inoue, T. Tateishi. J Chromatogr B., 789, 239(2003)

27 A. Onal, A. Oztunc. J Food Drug analysis., 14(1), 12(2006)

28. M. Hassan, T. Anderson, M. Niazi, K. Rhoss. Eur J Pharmacol., 60(4), 531(2004)

29. S. Warringtone, K. Baisley, K. Dunn, M. Boyce, A. Morocutti. Eur J Pharmacol., 62(9), 685(2004)

30. S.S. Qutab, S.N. Razzaq, I.U. Khan, M. Ashfaq, Z.A. Shuja. J Food Drug Anal., 15(2), 139(2007)

31. M. Ashfaq, I.U. Khan, S.S. Qutab, S.n. Razzaq. J Chil Chem Soc., 52(3), 1220(2007)

32. S.S. Qutab, S.N. Razzaq, M. Ashfaq, Z.A. Shuja, I.U. Khan I.U., Acta chromatographica, 19, 119(2007)

33. I.U. Khan, S. Sharif., M. Ashfaq, M.N. Asghar., J AOAC International, 91(4), 744(2008)

34. M. Ashfaq, I.U. Khan, M.N. Asghar. J Chil. Chem. Soc., 53(3), 1617(2008)

35. S.S. Qutab, S.N. Razzaq, M. Ashfaq, I.U. Khan, A.M. Mumtaz., J. Chil. Chem. Soc., 54(3), 234(2009)

36. I.U. Khan, S.M.S, Jillani, M. Ashfaq., Lat. Am. J. Pharm., 29, 1383(2010)

37. I.U. Khan, T. Kausar, M. Ashfaq, S. Sharif., 2010. J. Chil. Chem. Soc., 55(4), 461(2010)

38. S. Sharif, I.U. Khan, M. Ashfaq, M.S. Iqbal, S. Ahmad,. J. Anal. Chem., 65, 1029(2010)

39. S.N. Razzaq, I. Mariam, I.U. Khan, M. Ashfaq., J Liq. Chrom. Rel. Technol., 35, 651(2012)

40. ICH (Q2B) (1996) Note for guidance on validation of analytical procedures: methodology. International conference on Harmonization, IFPMA, Geneva. 